\title{
Modeling the Relationships among Mastery Goal Orientations, Positive Coping Strategy, and Motivational Beliefs in Science
}

\author{
Münevver Subaşi* \\ Department of Mathematics and Science Education, Hatay Mustafa Kemal University, Faculty of Education, Hatay, Turkey
}

*Corresponding Author: munevversubasi@gmail.com

\section{ABSTRACT}

This study aimed to investigate the relationships among mastery goal orientations (approach and avoidance), adaptive coping strategy (positive coping), and motivational beliefs (self-efficacy and task value) among middle school students in science. The study group consists of 249 students studying at four middle schools in one of the largest cities located in the eastern part of Turkey. The research data were collected using Achievement Goals Questionnaire, Academic Coping Inventory, and the Motivated Strategies for Learning Questionnaire. Structural equation modeling was performed using AMOS program to test the hypothesized relationships among constructs. The results showed that individuals with mastery goal orientation used more positive coping strategies. It was observed that individuals with higher self-efficacy had a higher ratio of using positive coping strategies. In addition, individuals with a high level of motivational beliefs used more mastery goal orientation. Furthermore, while mastery goal orientations positively predicted motivational beliefs and positive coping strategies, positive coping strategy was found to predict positively self-efficacy only. This study was a correlational study, but correlational studies did not help the establishment of a cause-effect (causality) relationship between the variables in question. Experimental studies can be conducted in the future to reveal the causes and effects related to the correlation between the relevant variables.

KEY WORDS: mastery goal orientations; motivational beliefs; positive coping; science

\section{INTRODUCTION}

$\wedge$ good academic motivation helps with the realization that learning is important not only in academic life but also in all areas of life itself. A student with a positive academic motivation is more enthusiastic to learn and believes in the importance of studying (Brown, 2009). Students' academic performances and achievement goal orientations are closely related (Ames, 1992). Achievement target orientation is situated in between the more specific individual goals and rather general global scale goals. Achievement goals focus on the causes and goals of individuals to accomplish a task (Pintrich and Schunk, 2002). Educational psychologists distinguish between the learning and performance goal orientations, which constitute achievement goal orientations (Ames and Archer, 1988; Dweck, 1986; Nicholls, 1984). There are many different ideas in terms of using success and talent, evaluation of errors and evaluation standards regarding learning, and performance goal orientations. The combination of these differences in terms of adequacy and goals both strengthens the achievement goal orientation and can increase the theoretical applicability (Pintrich, 2000). While students with performance goal orientations tend to exhibit their achievements to others, students with achievement goal orientation work to improve themselves rather than showing their success to others (Kaplan and Midgley, 1997). Individuals with performance goal orientation avoid difficult tasks and usually have low intrinsic motivation. On the other hand, individuals with mastery goal orientation are willing to take on difficult tasks and insist on achieving them. Their intrinsic motivation to perform the duties is very high. For these students, failure is not a personal deficiency, but a motivation that drives them to find new ways of working more (Ames, 1992; Ames and Archer, 1988).

Goal orientation is significantly related to coping strategies. Coping strategies are different methods people use to deal with stressful or negative situations or academic failure (Folkman and Moskowitz 2004). While some of these coping strategies have positive (adaptive) outcomes, others have negative (maladaptive) outcomes. Finding one's own mistakes, working harder, and seeking help could be given as examples for adaptive coping strategies; examples of maladaptive coping strategies include blaming others, ignoring one's own mistakes, and blaming oneself. In this study, positive overcoming was used, which is an adaptive coping strategy among the academic coping strategies developed by Tero and Connell (1984). In positive overcoming, the person seeks to know exactly where they made mistakes, analyzes these mistakes, and manages their time (Kaplan and Midgley, 1997). Individuals with mastery goal orientation tend to use adaptive coping strategies more often. Mastery goal orientation is positively correlated with the use of adaptive strategies such as positive overcoming (Friedel et al., 2007; Kahraman, 2011; Skaalvik, 2018). In addition, students who exhibit mastery goal orientation use adaptive coping strategies such as counseling, planning, and 
identifying the mistake to never to it again (Taye and Zhou, 2009). Problem-oriented coping strategies have positive outcomes and are closely related to mastery goal orientation (Brdar et al., 2006).

The current literature reveals that motivational beliefs and coping strategies are also inter-related. Individuals with high self-efficacy tend to use adaptive coping strategies more often (Devonport et al., 2003; Devenport and Lane, 2006; Hsiesh, 2005; Lane et al., 2002). If students have a high level of selfefficacy, they use adaptive coping strategies, which include adaptive features such as counseling, time management, and planning (Devenport and Lane, 2006; Lane et al., 2002). Individuals with high task value beliefs also use adaptive coping strategies more often (Hsiesh, 2005; Mantzicopoulos, 1997). Students are better motivated when they are focused on a task. Adaptive coping strategies help students to focus their attention to the task at hand (Hsiesh, 2005). In his study, Mantzicopoulos (1997) stated that students use positive coping strategies more often if they find the task assigned to them valuable, useful, and beneficial.

Self-efficacy and task value, which are among the motivational beliefs, are directly related to the goal orientations. The belief of self-efficacy can be defined broadly as a person's belief in successfully fulfilling a given task via putting in the energy, effort, and perseverance of the difficulties faced (Chemers et al., 2001). In addition, self-efficacy and students' success, motivation, and persistence in academic tasks are inter-related (Zimmerman, 2000). There is a positive correlation between self-efficacy and mastery goal orientations (Bong, 2001; Hsieh et al., 2007; Liem et al., 2008; Shim and Ryan, 2005). Students with high self-efficacy use approach goal orientation, while students with low self-efficacy tend to use avoidance goal orientations (Elliot and Church, 1997). The reasons for a student wanting to perform any given task define the task value (Eccles and Wigfield, 1995; 2002; Pintrich and Schunk, 2002). There is a positive correlation between mastery goal orientations and task value (Liem et al., 2008; Wolters et al., 1996). Students who find a task useful and interesting prefer to use mastery goal orientations more often. In this way, they become willing to learn and understand and develop their knowledge and skills (Bong, 2004; Hullerman et al., 2008; Xiang et al., 2004). Students who use mastery goal orientation feel more comfortable and safer when it comes to completing any given task successfully (Middleton and Midgley, 1997; Pintrich and De Groot, 1990).

When the related literature is examined, a correlation between the mastery goal orientations and positive coping strategies (Brdar et al., 2006; Friedel et al., 2007; Kahraman, 2011; Taye and Zhou, 2009); mastery goal orientations and task value (Bong, 2004; Hullerman et al., 2008; Lavasani et al., 2010; Liem et al., 2008; Wolters et al., 1996); and self-efficacy (Elliot and Church, 1997; Hsieh et al., 2007; Shim and Ryan, 2005) can be observed. There are also studies which examine the correlation between positive coping strategies and motivational beliefs (Devonport and Lane, 2006; Lane et al., 2002; Mantzicopoulos, 1997). However, studies which focus collectively on mastery goal orientations, positive coping strategies, and motivational beliefs are limited. In this study, the aim was to investigate the correlation between students' mastery goal orientations (approach and avoidance), adaptive coping strategies (positive coping), and motivational beliefs (task value and self-efficacy) for the science course. Mastery goal orientations are expected to be correlated with motivational beliefs through a positive coping strategy variable and directly predict the motivational beliefs; positive coping strategies are also expected to be in correlation with motivational beliefs (Figure 1).

\section{METHODS}

This correlational research method among quantitative research approaches examines the relationships between mastery goal orientations (mastery approach and mastery avoidance), adaptive coping strategies (positive coping), and motivational beliefs (self-efficacy and task value). It is impossible to establish a cause-effect relationship among the variables while examining their co-variation in correlational studies (Fraenkel and Wallen, 2006).

\section{Sample}

A total of 249 volunteer middle school students (109 girls, 130 boys) from four public schools in one of the largest cities in the eastern part of Turkey participated in the study. The convenient sampling was used during data collection that is schools were easily accessible for the researchers. A total of $38 \%$ of the participants were sixth-grade students, $40 \%$ were seventh, and $21 \%$ were eighth. The mean age of participants was 12.62 .

\section{Instruments}

Perceived mastery goal orientations were assessed through the "Achievement Goals Questionnaire" (Elliot and McGregor, 2001) which has 15 items in four subscales: Mastery approach, mastery avoidance, performance approach, and performance avoidance. Two subscales were used in this study: Mastery approach (e.g., "I desire to completely master the material that presented in this class") and mastery avoidance (e.g., "I just want to avoid doing poorly in this class"). Students responded using a five-point Likert scale, ranging from 1 (strongly disagree) to 5 (strongly agree). The instrument was adopted into Turkish by Senler and Sungur (2007). In the present study, the Cronbach alpha coefficient was found to be .76 for the mastery approach and avoidance subscales.

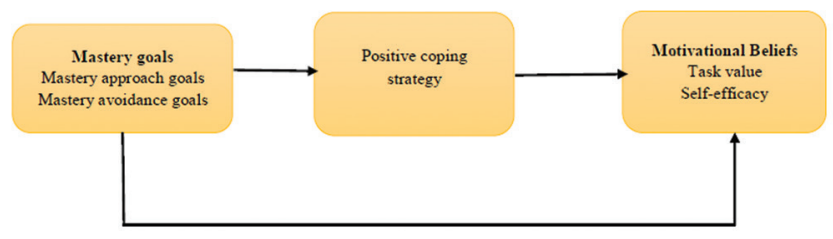

Figure 1: Proposed model 
Coping strategies were assessed through the "Academic Coping Inventory" (Tero and Connell, 1984) which has 13 items in four subscales: positive coping, denial coping, projective coping, and non-coping. A positive coping subscale was used in this study (e.g., "I would try to see what I did wrong"). Students responded using a five-point Likert scale, ranging from 1 (strongly disagree) to 5 (strongly agree). The instrument was adopted into Turkish by Kahraman and Sungur (2013). In the present study, the Cronbach alpha coefficient was found to be 0.79 for the positive coping subscale.

Self-efficacy and task value were assessed through the self-efficacy for learning and performance subscale of the "Motivated Strategies for Learning Questionnaire" (Pintrich et al., 1991). The self-efficacy subscale has seven items (e.g., "I believe I will receive an excellent grade in the science class"). The task value subscale has six items (e.g., "I think I will be able to use what I learn in this course in other courses). Students responded using a seven-point Likert scale, ranging from 1 (not at all true of me) to 7 (very true of me). The instrument was adapted into Turkish by Sungur (2004). In the present study, the Cronbach alpha coefficient was found to be 0.86 for the self-efficacy subscale and 0.75 for task value.

\section{Procedure}

The data collected during regular class hours in the 2018-2019 academic year. Before data collecting, some information was provided to the students about the research and how to fill instruments.

\section{Data Analysis}

Descriptive and inferential statistics were conducted using variables. The variables of the study were investigated in terms of mean, standard deviation in part of descriptive statistics; the proposed model was tested through the path analysis in part of inferential statistics. Descriptive statistics were computed using IBM SPSS Statistics (version 22) and path analysis was performed using the AMOS program.

\section{RESULTS}

The results of the study are presented in two parts: Descriptive and inferential statistics. The variables of the study were investigated in terms of mean and standard deviation in the descriptive statistic part. The proposed model was tested through the path analysis in the inferential statistics part.

\section{Descriptive Statistics for Variables}

Mean scores for mastery goal orientations on a five-point scale indicated that students had a mastery approach and mastery avoidance goals at moderate to high levels (Table 1). The mastery approach goals had a high mean score. While mastery avoidance goals had a lower mean score, it was still above the mid-point of the scale. Mean scores for coping strategies on the five-point scale indicated that students tended to demonstrate positive coping at high levels in science. Mean score of motivational beliefs had moderate to high levels. Mean score for task value was more higher than mean score for self-efficacy. Mean score for task value used a seven-point scale indicated that middle school students had a high level of task value in science (Mean $=5.72$ ). Mean score for self-efficacy was above the mid-point of the scale.

\section{Inferential Statistics}

The relationships between middle grade students' perceived mastery goals, adaptive coping strategies, and motivational beliefs were examined by proposing and testing a path model (Figure 2) model-to-data fit $\left(\chi^{2} / \mathrm{df}=1.44\right.$, goodness-of-fit index $[\mathrm{GFI}]=0.904$, comparative fit index $[\mathrm{CFI}]=0.952$, root mean square error of approximation [RMSEA] $=0.04$, adjusted goodness-of-fit index $[\mathrm{AGFI}]=0.88$ ). While evaluating model fit, it is recommended to use various fit indices together. CFI, GFI RMSEA, and AGFI were examined. For a good model fit, it is recommended that GFI, CFI, and AGFI to be $>0.90$ while RMSEA to be $<0.05$ (Şimşek, 2007). After gaining evidence about the appropriateness of the conceptual model, parameter estimates (standardized coefficients) were examined next. The standardized coefficients are presented in Table 2 and significant path coefficients are displayed in Figure 2.

When the predictive effect of adaptive coping strategy and the mastery goal orientations (mastery approach and avoidance goals) on each motivational beliefs (task value and selfefficacy) were examined, it was seen that they explained $23 \%$ of the variance in self-efficacy. Parameters estimates revealed that positive coping $(\beta=0.41)$ and mastery approach goals $(\beta=0.18)$ were statistically significantly and positively predicted self-efficacy (Table 2). According to these results, individuals who trust their abilities and believe that they will succeed in the science class usually seek for the sources of their mistakes and put in more effort to improve themselves and learn better.

The amount of explained variance in task value was $37 \%$. Mastery avoidance goals were statistically significantly and positively

\begin{tabular}{lccc}
\hline \multicolumn{4}{l}{ Table 1: Descriptive statistics for students' perceptions of } \\
mastery goals, coping strategies, and motivational beliefs
\end{tabular}

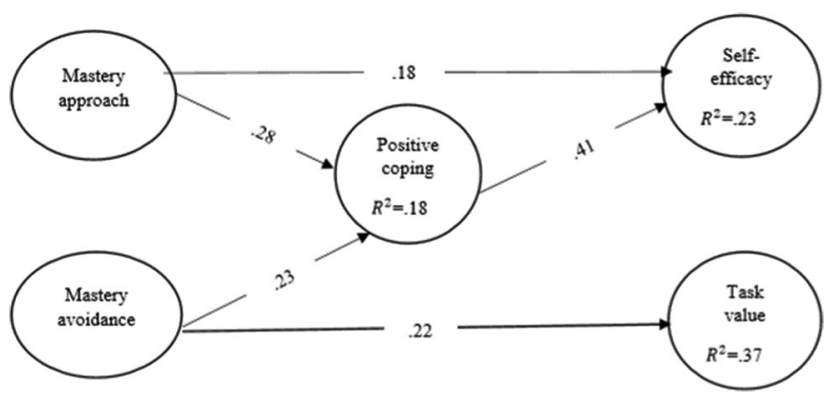

Figure 2: Model with significant path coefficients only 


\begin{tabular}{|c|c|c|c|c|c|}
\hline Effect & Standardize $\beta$ & SE of the estimates & $t$ & $\rho$ & $\mathbf{R}^{2}$ \\
\hline \multicolumn{6}{|l|}{ Self-efficacy } \\
\hline Positive coping & 0.415 & 0.143 & 4.856 & $* * *$ & 0.232 \\
\hline Mastery approach & 0.183 & 0.158 & 2.328 & 0.020 & \\
\hline Mastery avoidance & -0.092 & 0.122 & -1.115 & 0.256 & \\
\hline \multicolumn{6}{|l|}{ Task value } \\
\hline Positive coping & 0.153 & 0.076 & 1.682 & 0.093 & 0.371 \\
\hline Mastery approach & -0.054 & 0.078 & -0.696 & 0.487 & \\
\hline Mastery avoidance & 0.222 & 0.067 & 2.470 & 0.014 & \\
\hline \multicolumn{6}{|l|}{ Positive coping } \\
\hline Mastery approach & 0.281 & 0.098 & 3.342 & $* * *$ & 0.180 \\
\hline Mastery avoidance & 0.238 & 0.076 & 2.783 & 0.005 & \\
\hline
\end{tabular}

predicted task value. These findings suggest that students finding a task useful and enjoyable in science class avoid misunderstanding.

Furthermore, results showed that mastery goal orientations explained $18 \%$ of the variance in a positive coping strategy. Mastery approach goals $(\beta=0.28)$ and mastery avoidance goals $(\beta=0.23)$ (Table 2 ) were statistically significantly and positively associated with a positive coping strategy. This finding indicates that students who adopt the mastery goal orientation approach in science class learn from their mistakes and prefer to improve themselves and avoid misunderstanding by identifying the sources of their mistakes.

\section{DISCUSSION, CONCLUSIONS, AND LIMITATIONS}

In this study, the correlations between students' mastery goal orientations, positive coping strategies, and motivational beliefs (task value and self-efficacy) were investigated. According to the results obtained from the research, individuals with mastery goal orientation used positive coping strategies more often. This result obtained from the study is supported by previous studies examining the correlation between mastery goal orientations and coping strategies (Brdar et al., 2006; Friedel et al., 2007; Kahraman, 2011; Skaalvik, 2018; Taye and Zhou, 2009). Skaalvik (2018) revealed in his study in mathematics class that mastery goal orientations strongly predicted the use of adaptive coping strategies (problem-oriented coping). Similarly, Kahraman (2011), who examined the correlation between mastery goal orientation and coping strategies in science teaching, revealed that students with mastery goal orientation (approach) used adaptive coping strategies more often. Taye and Zhou (2009) showed that mastery goal orientations are positive predictors of adaptive coping strategies such as planning. In a nutshell, when the relevant literature is analyzed, individuals focused on self-improvement and understanding were persistent in the face of difficulties they encountered in learning environments; and exhibited adaptive behaviors such as counseling, planning, identifying the mistake, and not doing it again.

Another hypothesis that was expected to be confirmed with the research was that individuals with high motivational beliefs would use adaptive coping strategies more often. This hypothesis is presented separately for self-efficacy and task value. The hypothesis that individuals with high selfefficacy tend to use adaptive coping strategies more often was confirmed with the study. The findings obtained also conform to the relevant literature (Devonport et al., 2003; Devonport and Lane, 2006; Hsiesh, 2005; Lane et al., 2002). Devonport and Lane (2006) stated in their research that individuals with high self-efficacy used adaptive coping strategies more often. If individuals with high self-efficacy could develop a high self-efficacy belief in a certain field, they could set personal goals related to this field, did not give up easily in the face of problems they encounter, and could exhibit a positive attitude for the future by seeking different solutions to solve their problems (Henson, 2001; Pajares, 2002). However, contrary to the literature, there was no statistically significant correlation between task value and adaptive coping strategies. This result which is conflicting with the literature could be due to sociocultural impacts. Turkey has an exam-oriented and competitive education system. Students focus on the tasks given not only because they are fun and beneficial to them but also to be placed in a better school so that they can obtain a better status in the community. In such societies, self-improvement and identifying errors to correct them are secondary, as social acceptance is usually more important than self-improvement (Markus et al., 1996; Elliot et al., 2001).

According to another result obtained from the study, individuals with high levels of motivational beliefs (task value - self-efficacy) used mastery goal orientation more often. The result obtained was presented separately for task value and self-efficacy. Based on the result, individuals with mastery goal orientation should also exhibit high levels of task value. While the related literature emphasizes a positive correlation between task value and learning approach goal orientation, it also emphasizes a negative correlation with learning avoidance (Hullerman et al., 2008; Liem et al., 2008; Wolters et al., 1996; Xiang et al., 2004). However, the result obtained from this study points out to a positive correlation between the task value and learning avoidance. The results obtained contradict the relevant literature. However, a similar 
result is compatible with the results obtained by Kahraman (2011) and Bong (2001). Kahraman (2011), who performed a study on $7^{\text {th }}$-grade science class student in Turkey on relevant variables, found a positive correlation between task value and learning avoidance. Similarly, Bong (2001), in his Korean study, reached to a similar conclusion and found a positive correlation between learning avoidance and task value. These results obtained in both studies which contradict with the other results of the literature have been explained with different cultural values of the countries that they were performed. In countries with collectivist cultural structures such as Turkey and Korea, preventing negative consequences is an important part of life. In countries with collectivist cultural structures, society is more important than any individual goals (Markus et al., 1996; Elliot et al., 2001). Students avoid negative consequences and misunderstanding by utilizing learning avoidance goal orientation. Similarly, in the studies of Middleton and Midgley (1997) and Pintrich and De Groot (1990), students with high task value stated that they avoided any misunderstanding and made efforts to fulfill the task that they have been assigned. The hypothesis which was confirmed with the results of the study is that individuals with a high level of self-efficacy tend to use learning approach goal orientation more often. The result obtained is supported by the relevant literature (Akın, 2008; Bong, 2001; Hsieh et al., 2007; Ames, 1992; Philips and Gully, 1997; Shim and Ryan, 2005). Liem et al. (2008) stated in their Singaporean study that individuals with high levels of self-efficacy used mastery goal orientation more often. In other studies, similar results were obtained and it was revealed that individuals with high levels of self-efficacy use mastery goal orientation more often. In summary, students who strive to increase their abilities and master their skills feel more confident about themselves.

This study has some limitations that should be mentioned. The data obtained from the study were based solely on the answers given by the students in the data collection tools. The answers reflect students' perspectives only. Student perceptions can be supported by observational data by making longterm observations in future studies. Another limitation is the fact that study data were collected from students in a single application. A longitudinal study could be carried out with more than one application using the relevant variables. Another limitation that should be mentioned is the method used in the study. Correlational studies do not help the establishment of a cause-effect (causality) relationship between the variables in question. Experimental studies can be conducted in the future to reveal the causes and effects related to the correlation between the relevant variables.

\section{REFERENCES}

Akın, A. (2008). Self-efficacy, achievement goals and depression, anxiety, and stres: A structural equation modeling. World Applied Sciences Journal, 3(5), 725-732.

Ames, C. (1992). Classrooms: Goals, structures, and student motivation. Journal of Educational Psychology, 84(3), 261-271.

Ames, C., \& Archer, J. (1988). Achievement goals in the classroom: Students' learning strategies and motivation processes. Journal of Educational Psychology, 80(3), 260-267

Bong, M. (2001). Between-and within-domain relations of academic motivation among middle and high school students: Self-efficacy, task value, and achievement goals. Journal of Educational Psychology, 93(1), 23-34.

Bong, M. (2004). Academic motivation in self-efficacy, task value, achievement goal orientations, and attributional beliefs. The Journal of Educational Research, 97(6), 287-297.

Brdar, I., Rijavec, M., \& Loncaric, D. (2006). Goal orientations, coping with school failure and school achievement. European Journal of Psychology of Education, 21(1), 53-70.

Brown, M.B. (2009). Academic motivation: Strategies for students. Communique Handout, 38(1), 1-4.

Chemers, M.M., Hu, L.T., \& Garcia, B.F. (2001). Academic self-efficacy and first year college student performance and adjustment. Journal of Educational Psychology, 93(1), 55-64.

Devonport, T.D., Lane, A.M., Milton, K.E., \& Williams, L. (2003). Selfefficacy as a predictor of strategies used to cope with dissertation stress. In: Paper Presented at the Annual Conference of the British Psychological Society, Bournemouth.

Devonport, T.J., \& Lane, A.M. (2006). Relationships between self-efficacy, coping and student retention. Social Behavior and Personality: An International Journal, 34(2), 127-138.

Dweck, C.S. (1986). Motivational processes affecting learning. American Psychologist, 41, 1040-1048.

Eccles, J.S., \& Wigfield, A. (1995). In the mind of the actor: The structure of adolescents' achievement task values and expectancy-related beliefs. Personality and Social Psychology Bulletin, 21(3), 215-225.

Eccles, J.S., \& Wigfield, A. (2002). Motivational beliefs, values, and goals. Annual Review of Psychology, 53(1), 109-132.

Elliot, A., \& McGregor, H. (2001). A 2 X 2 achievement goal framework. Journal of Personality and Social Psychology, 80(3), 501-519.

Elliot, A.J., \& Church, M.A. (1997). A hierarchical model of approach and avoidance achievement motivation. Journal of Personality and Social Psychology, 72, 218-232.

Elliot, A.J., Chirkov, V.I., Kim, Y., \& Sheldon, K.M. (2001). A crosscultural analysis of avoidance (relative to approach) personal goals. Psychological Science, 12(6), 505-510.

Folkman, S., \& Moskowitz, J.T. (2004). Coping: Pitfalls and promise. Annual Reviews of Psychology, 55, 745-774.

Fraenkel, J.R., \& Wallen, N.E. (2006). How to Design and Evaluate Research in Education. New York: McGrawhill, Inc.

Friedel, J.M., Cortina, K.S., Turner, J.C., \& Midgley, C. (2007). Achievement goals, efficacy beliefs and coping strategies in mathematics: The roles of perceived parent and teacher goal emphases. Contemporary Educational Psychology, 32(3), 434-458.

Henson, R.K. (2001). The effects of participation in teacher research on teacher efficacy. Teaching and Teacher Education, 17, 819-836.

Hsieh, P., Sullivan, J.R., \& Guerra, N.S. (2007). A closer look at college students: Self efficacy and goal orientation. Journal of Advanced Academia, 18, 454-476.

Hsieh, Y.P. (2005). The Interrelationships Among Goal Orientation, Coping, and Achievement Motivation after Perceived Academic Failures, Doctoral Dissertation. United States: The University of Texas at Austin.

Hulleman, C.S., Durik, A.M., Schweigert, S.A., \& Harackiewicz, J.M. (2008). Task values, achievement goals, and interest: An integrative analysis. Journal of Educational Psychology, 100, 398-416.

Kahraman, N. (2011). Antecedents and Consequences of Achievement Goals, Unpublished Doctorate Dissertation. Turkey: Middle East Technical University.

Kahraman, N., \& Sungur, S. (2013). Antecedents and consequences of middle school students' achievement goals in science. The Asia-Pacific Education Researcher, 22(1), 45-60.

Kaplan, A., \& Midgley, C. (1997). The effect of achievement goals: Does level of perceived academic competence make a difference? Contemporary Educational Psychology, 22(4), 415-435.

Lane, A.M., Jones, L., \& Stevens, M. (2002). Coping with failure: The effects of self-esteem and coping on changes in self-efficacy. Journal of Sport Behavior, 25, 331-345. 
Lavasani, M.G., Malahmadi, E., \& Amani, J. (2010). The role of self-efficacy, task value, and achievement goals in predicting learning approaches and mathematics achievement. Procedia-Social and Behavioral Sciences, 5, 942-947.

Liem, A.D., Lau, S., \& Nie, Y. (2008). The role of self-efficacy, task value, and achievement goals in predicting learning strategies, task disengagement, peer relationship, and achievement outcome. Contemporary Educational Psychology, 33, 486-512.

Mantzicopoulos, P. (1997). How do children cope with school failure? A study of social/emotional factors related to children's coping strategies. Psychology in the Schools, 34(3), 229-237.

Middleton, M., \& Midgley, C. (1997). Avoiding the demonstration of lack of ability: An underexplored aspect of goal orientation. Journal Educational Psychology, 89, 710-718.

Nicholls, J. (1984). Achievement motivation: Conceptions of ability, subjective experience, task choice, and performance. Psychological Review, 91, 328-346.

Pajares, F. (2002). Gender and perceived self-efficacy in self-regulated learning. Theory into Practice, 41(2), 116-125.

Philips, J.M., \& Gully, S.M. (1997). Role of goal orientation, ability, need for achievement, and locus of control in the selfl-efficacy and goal-setting process. Journal of Applied Psychology, 82(5), 792-802.

Pintrich, P., Smith, D., Garcia, T., \& McKeachie, W. (1991). A Manual for the Use of the Motivated Strategies for Learning Questionnaire, Technical Report No. 91-B-004. United States: The Regents of The University of Michigan.

Pintrich, P.R. (2000). An achievement goal theory perspective on issues in motivation terminology, theory, and research. Contemporary Educational Psychology, 25(1), 92-104

Pintrich, P.R., \& de Groot, E.V. (1990). Motivational and self-regulated learning components of classroom academic performance. Journal of Educational Psychology, 82(1), 33-40.
Pintrich, P.R., \& Schunk, D.H. (2002). Motivation in Education: Theory, Research, and Applications. $2^{\text {nd }}$ ed. United States: Prentice Hall Merrill.

Senler, B., \& Sungur, S. (2007). Hedef Yonelimi Anketinin Türkçe'ye Çevrilmesi ve Adaptasyonu [Translation and Adaptation of Achievement Goals Questionnaire to Turkish]. Ankara, Turkey: Paper Presented at Ulusal Ilkogretim Kongresi.

Shim, S., \& Ryan, A. (2005). Changes in self efficacy, challenge avoidance, and intrinsic value in response to grades: The role of achievement goals The Journal of Experimental Education, 73(4), 333-349.

Skaalvik, E.M. (2018). Mathematics anxiety and coping strategies among middle school students: Relations with students' achievement goal orientations and level of performance. Social Psychology of Education, 21, 709-723.

Sungur, S. (2004). An Implementation of Problem Based Learning in High School Biology Courses, Master Thesis. Ankara: The Middle East Technical University.

Simşek, Ö.F. (2007). Yapısal Eșitlik Modellemesine Giriș: Temel İlkeler ve Lisrel Uygulamaları. Ankara: Ekinoks.

Taye, E.A., \& Zhou, Z. (2009). Effects of goal orientations on coping strategies and self-efficacy for Ethiopian University students in their academic life. Pakistan Journal of Social Sciences, 6(6), 372-375.

Tero, P.F., \& Connell, J.P. (1984). When Children Think They've Failed: An Academic Coping Inventory. New Orleans, Louisiana: Paper Presented at the Annual Meeting of the American Educational Research Association.

Wolters, C.A., Yu, S.L., \& Pintrich, P.R. (1996). The relation between goal orientation and students' motivational beliefs and self-regulated learning. Learning and Individual Differences, 8, 211-238.

Xiang, P., McBride, R., \& Bruene, A. (2004). Fourth graders' motivation in an elementary physical education running program. The Elementary School Journal, 104, 253-266.

Zimmerman, B.J. (2000). Self-efficacy: An essential motive to learn. Contemporary Educational Psychology, 25(1), 82-91. 